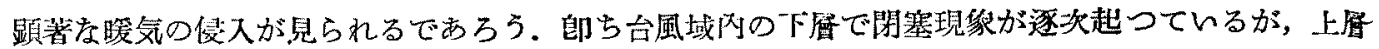
では暖気の占める区域が病がりつ」あるここがわかる。

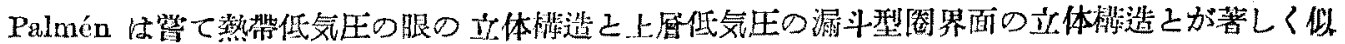
ているととをしめしそ（文献 3)。その議論は必ら秃し全面的に承服しがたい點があるけれど も，上屏低気圧域內で疑似閉塞現缘がおこるこ己と，晚秋中緯度に侵入して来る台風の域內で疑似

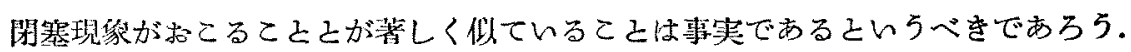

\title{
文献
}

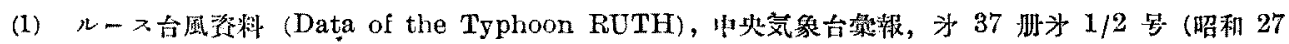
年) , 93-104 页特に 97-97 页.

(2) E. Palmén: The Aerology of Extratropical Disturbances, Compendium of Meteorology (1951)，599-620 又住地球物理学文阔抄为 4 集，为 5 号 (炤利 27 年).

(3) E. Palmén: On the Formation and Structure of Tropical Hurricanes, Geophysica, No. 3

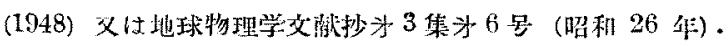

地表風中の煙の垂直拡散に関する注意

井上栄 一*

\section{Some Remarks on the Vertical Diffusion of Smoke near the Ground}

\author{
E. Inoue \\ (Division of Meteonology, National Institute of Agricultural Sciences, \\ Nistigahara, Tokyo)
}

The author deals with the vertical diffusion width of smoke in the wind near the ground. At first the diffusion phenomena are clearly separated in two states, i.e., the transient and the ultimate state, and also in two zones, $i . r$, the I-class and the II-class zone. These separations are shown to be possible by means of the mutual comparisons of the Lagrangian averaging-time and the life-time of the absolute largest turbulon in the flow, and also of the Lagrangian process-time and the life-time of the effective largest turbulon.

As to the ultimate state of the vertical turbulent diffusion of smoke near the ground, the theoretical results are compared with recent F. A. Record's (1951) experimental ones in general agreements.

On the other hand, concerning O. G. Sutton's (1951) recent question about the inter-

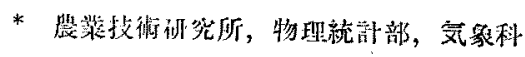


relation between the smoke width and the averaging-time the author presents a certain reasonable explanation making use of the concept of the transient state of vertical diffusion.

\section{§1. まえがき}

大気の乱流泫散に関して著者（Inoue 1950；1951 a,d) は最近 A. N. Kolmogoroff (1941) K 上つてはじめられた乱れの相似假說に從らある取报いの方法を提示した。 また他において著者

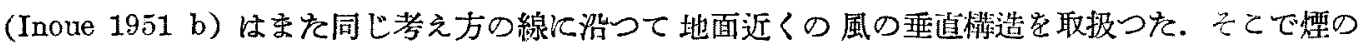
垂遖拡散の多くの特性が純粹に理諭的な見地から予言されるようになつた (Inoue $1951 \mathrm{ad}$ d). 雪 Kもつ之最近に著者は幸に F.A.Record（1951）によつて行われを地面近くの煙の垂道琉散に関 する興味ある実驗結果を知る機会を持つてとが出来だ。

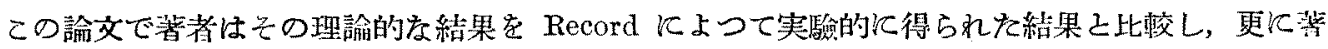
者の理諭的見地之大気拡散の問題で可成り行きわたつている O. G. Sutton (1932, 1934, 1947， 1949）の見地之の間の相違を明白にすること沉つとめている.

\section{§ 2. 大気の垂直擴散に関する理論的結果}

一般汇乱流の著しい病散能力は流れの中に存在している乱子の特別な蓮動によるもの之考えられ

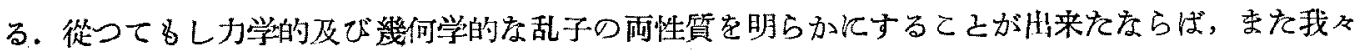

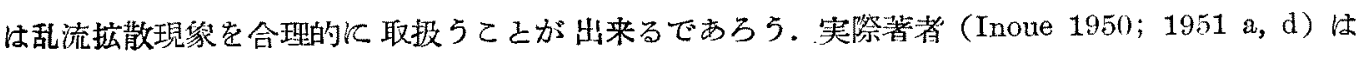
乙れらの問題を考え, いわゆる Lagrange 相関係数 $R(\xi)$ (G. I. Taylor 1921) 亿関して二, 三の 結果が得られている. この係数は Lagrange 流の意味における乱子スベクトルと，丁度 Euler 相

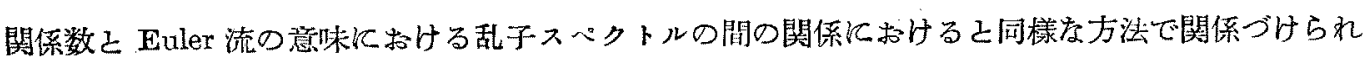
る.

Lagrange 流の意味にょける乱子スペクトル，即ち Lagrange 振動数 $n$ で表現される乱子スペク トルは乱れの相似假說を使つて次の形で得られる:

$$
F(n) \sim \varepsilon n^{-2},
$$

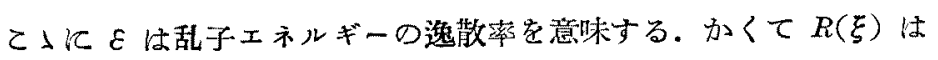

$$
R(\xi)=1-\text { const. }\left(\xi / \tau_{0} \text {, effect. }\right), 0<\xi \ll \tau_{0} \text {, effect. }
$$

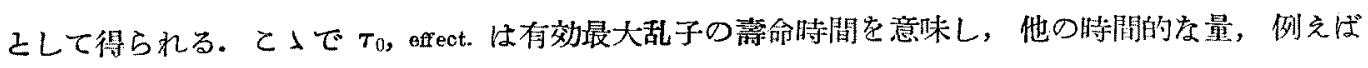

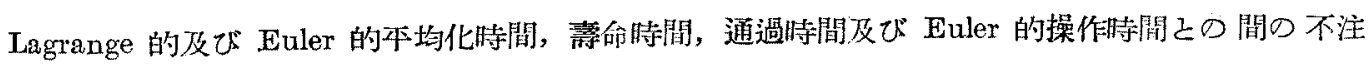

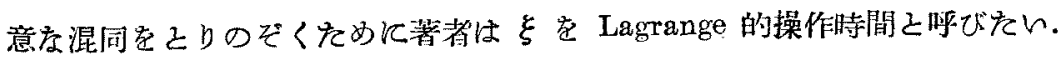

*著者は 1951 年 6 月に行われた Symposium on Atmospheric Turbulence in the Boundary Layer, M. I. T., に出塴する機會を持つた。この機会を持ち得たことついて, M. I. T. D Dr. E. Wendell Hewson に厚く感謝する。 


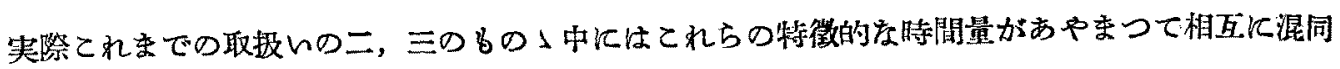

\section{されている.}

大気や海洋の上5な巨大乱流の中では，有効最大乱子の概念は特に重要であり，それは平均化 時間によつて相端的に決定される。著者は Lagrange 的平均化時間を $T_{* *}$ で示し，それを Euler

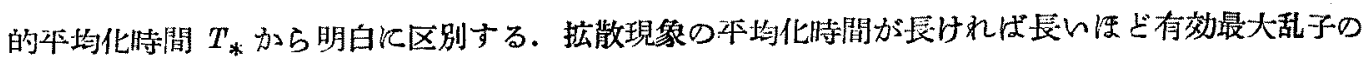

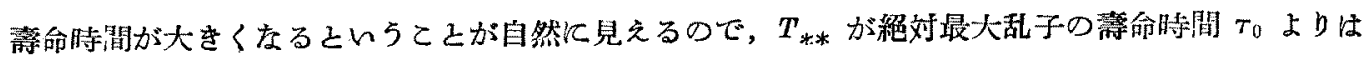
大をくないものとして，

$$
\tau_{0} \text {, effect. } \infty T_{* *}
$$

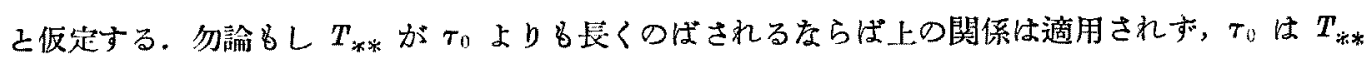

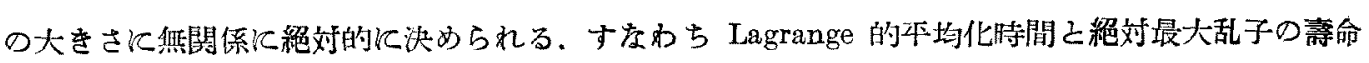
時間之の比によつて印づけられる次のような二つの事態がある:

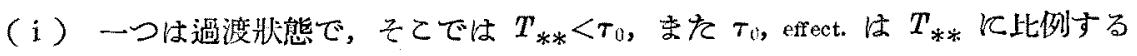

（ii）他は終局狀態で，そてでは $T_{* *}>\tau_{0}$ ，また $\tau_{0}$, effect. は $\tau_{0}$ に一致する.この休態では $\tau_{0}$, effect. 估当はや平均化時間には関係しない。

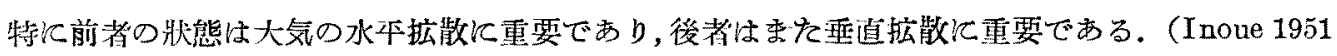

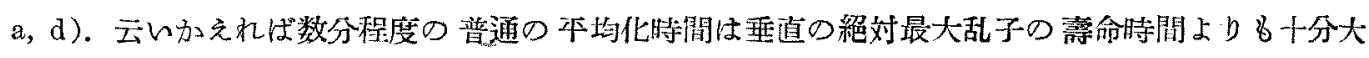
きくすり得るが，水平のるのよりは小さいるのよみをされる.

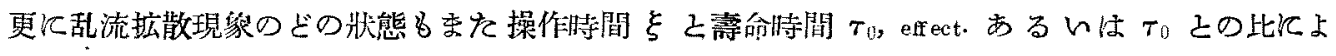

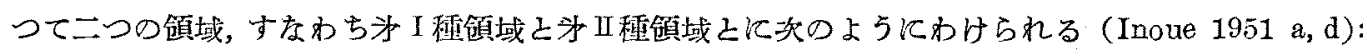

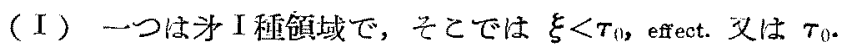

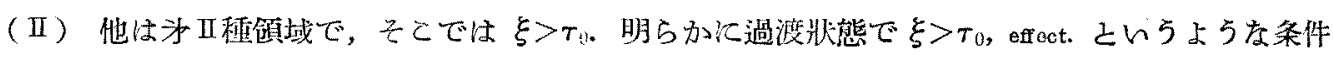

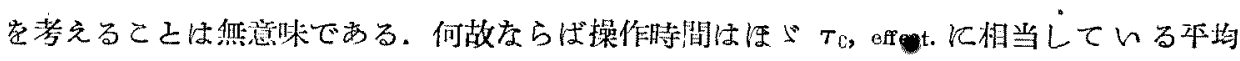
化時間よりる大きくはあり得存ん。

最近の論交で蕃者（Inoue 1951 b，c）は地表面近くの風の垂直權造を己りあつかい，垂直方向の 風の息 $\left\langle w^{2}>^{1 / 2} / U \sim V_{*} / U\right.$ 己垂直方向の乱流 Reynolds 数 $U Z / K Z \sim\left(U / V_{*}\right) \cdot\left(Z / \Lambda_{z}\right)$ が共沈ある 定まつた高さ $a$ におりる作均風速 $U(a)$ 亿留関係であるから, 垂道方向の乱流拡散現像の幾何学

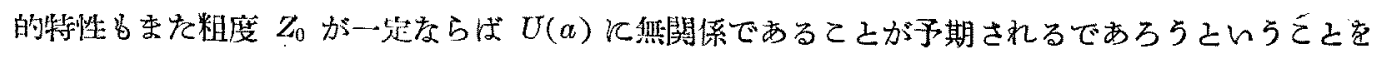

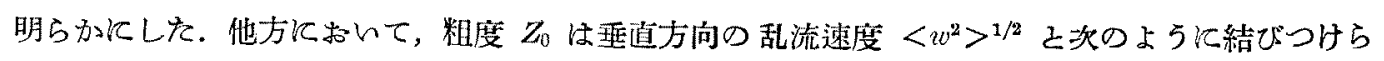
れる (Inoue 1952):

$$
\left\langle w^{2}>^{1 / 2} \sim V_{*} \sim U(a) \cdot\left(\log \frac{a}{Z_{0}}\right)\right.
$$

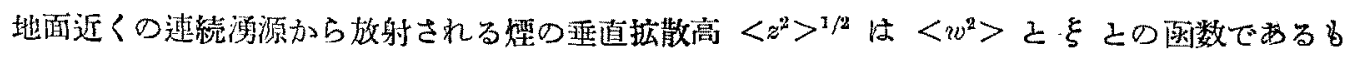


のと考えられる. そして $\left.<z^{2}\right\rangle^{1 / 2}$ は形式的に

$$
\left.\left.\left\langle z^{2}\right\rangle^{1 / 2} \sim<w^{2}\right\rangle^{1 / 2} \cdot \xi \sim<w^{2}\right\rangle^{1 / 2} \cdot x / U(a)
$$

之表現され得る.こなに

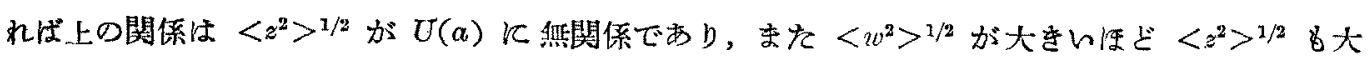

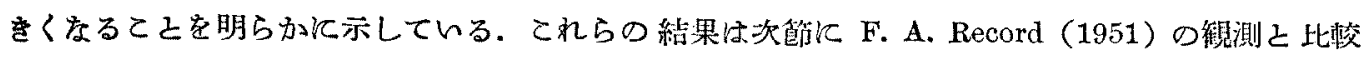
される。

\section{§ 3. 今の理論的結果と実讶的結果との比皎}

Massachüetts 工科大学で行われた境界㑛內の大気乱流関する最近の Symposium で，F.A.

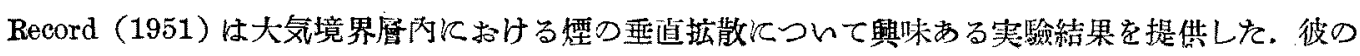

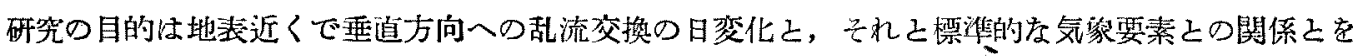
測るととであつた．彼は地表面における煙の連続的な点源を使用し，煙の苹道抎散の二，三の特

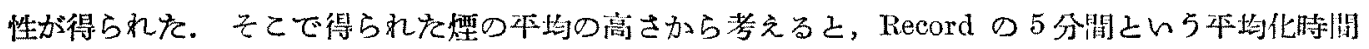

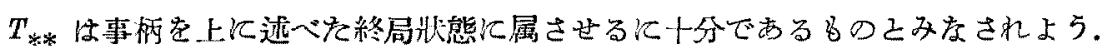

そてでもし地表面の粗度 $Z_{3}$ が一管であるならば，一定の距離 $x$ で得られる煙の高さは一起の

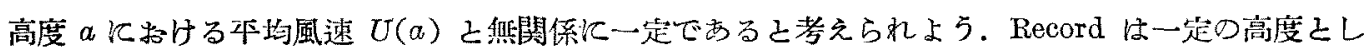
て 144 吹をえらんだ，著者には Record の結果が実際に煙の高さ $\left\langle z^{2}\right\rangle^{1 / 2}$ が平均風速 $U(a)$ に

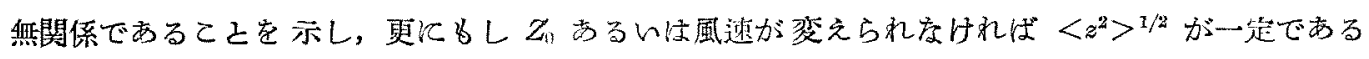
てこを暗示しているように思われる。

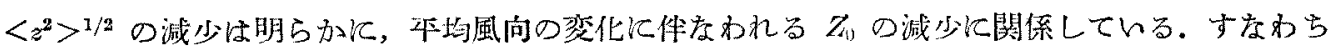

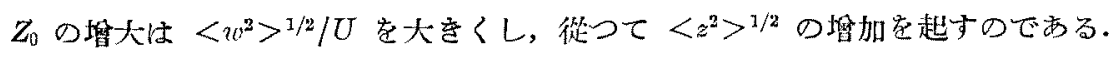

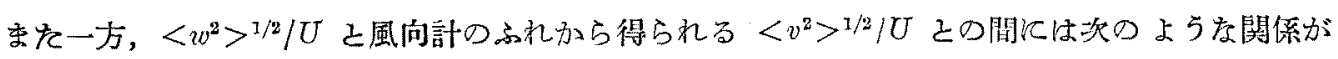
存在する (Inone 1952):

$$
\left\langle v^{2}>^{1 / 2} \sim\left\langle u^{2}\right\rangle^{1 / 2} \cdot T_{*}^{2 / 3} \cdot U^{-5 / 3}(a) \cdot Z \cdot\left(\log \frac{Z}{Z_{0}}\right)^{-1} \cdot\left(\log \frac{a}{Z_{0}}\right)^{5 / 3}\right.
$$

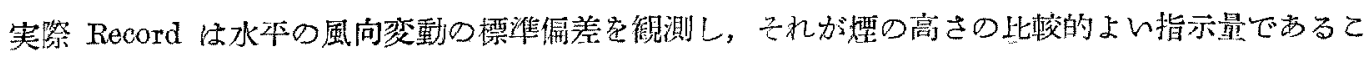
之を指摘した. Record の諭文には変動の観測に対する Euler 的平均化時間 $T_{*}$ が何多言及されて い索いが，著者は $T_{*}$ が一是に保をれていたもの上想像しても許されるである5.

\section{§ 4. O. G. Sutton の理論的結果と実驗結果との比較}

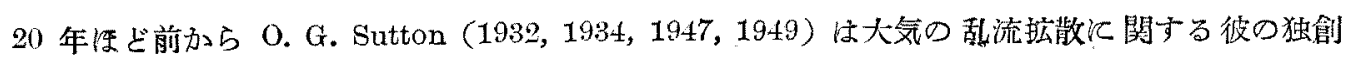

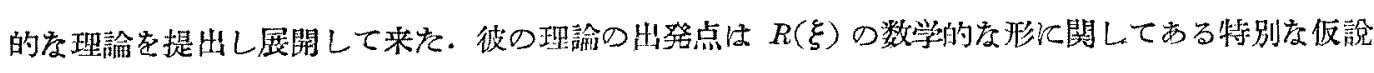

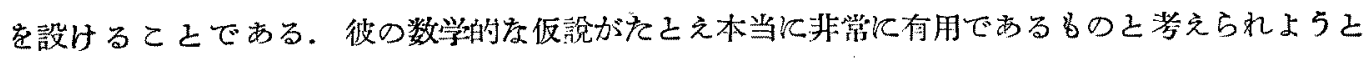
も，それらが物理的な見地から十分合理的である之は見なされ得ない. Sutton 理論の最も致俞的 
な久陷の一つは，それらが操作時間，壽命時閒及び平均化時間の間の区別をあまりはつきり之考え ていないとんう事実にあるよ5著者には見える。

上飞述へられを論文で F. A. Record b彼の実驗的結果を, 明らか次 Sutton の考文方の線に沿 5 E. L. Deacon (1949) の理諭加ら数学的化 得られる結果亡比較しており，そのよ5な数学的店

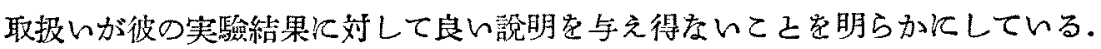

一方 Sutton（1951）\&この論文の最初汇述へられたと同し Symposium で “Some Unsolved Problems in the Physics of the Earth's Boundary Layer" こん5題の興味ある論交を発表して

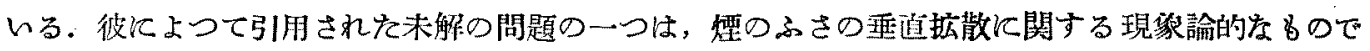

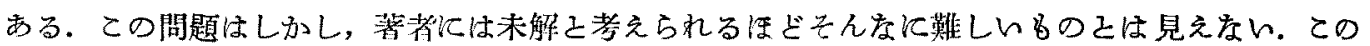
困難は主として Sutton 理論の中で平均化時閒の考察が完全に好けているという事実によるよ5に 見える，彼は次の上5に云5，「地表面之ある高さ之で 発生された煙のふさの写真は，煙の瞬間的

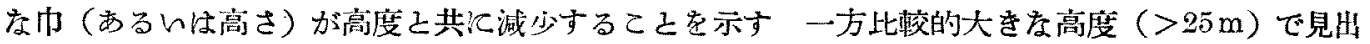
される Eddy は揚げられた煙の高められたゆるいふれを起すというある証拠があるから，長い特

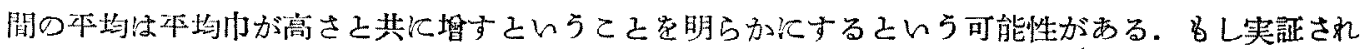

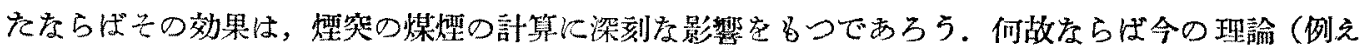
ば Sutton 1947) は煙のひろがりが，拡散のスケールが源の地面からの高さと共沉減少するとい5 大気の中で起ることを仮坨しているからである…」

上の現像諭的度相違はしかし，乱流拡散の過渡狀態之終局狀態乙の概念を使つて次のよ5に非常 亿簡單に說明されるこよが蜊来る：

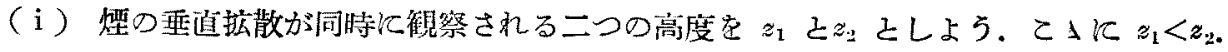

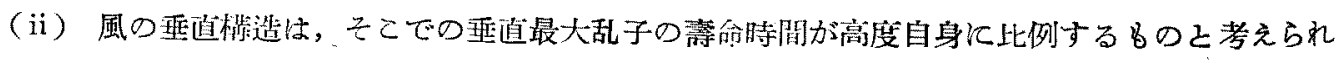
る風速の刘数分布で裴わされるものとしよう，從つて

$$
\tau_{0, z_{1}}<\tau_{0, z_{2}}
$$

となる。

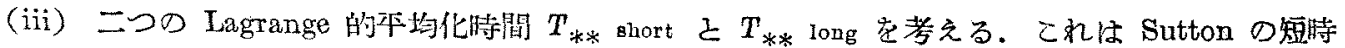
閒平均と辰侍䦐平均とにそれぞれ対応するであるう。

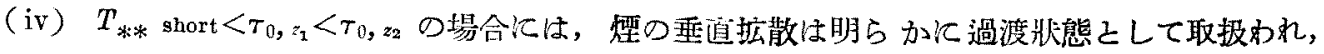

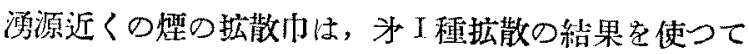

$$
\begin{aligned}
\left\langle z^{2}\right\rangle_{1} & =\frac{\left\langle w^{2}\right\rangle^{1 / 2}}{U} x, \\
\left\langle z^{2}\right\rangle_{2}^{1 / 2} & =\frac{\left\langle w^{2}\right\rangle^{1 / 2}}{U} x \\
& -10-
\end{aligned}
$$




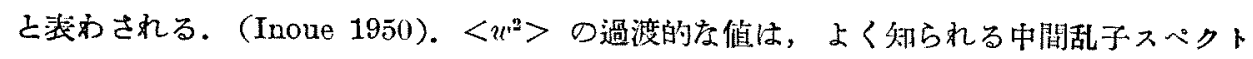
ルの $-5 / 3$ 邦則を使つてほよ゙

$$
\begin{aligned}
& \left\langle w^{2}\right\rangle_{1} / V_{*}{ }^{2} \sim T_{* *} / \tau_{0, z_{1}}, \\
& \left\langle w^{2}\right\rangle_{2} / V_{*}{ }^{2} \sim T_{* *} / \tau_{0}, z_{2} .
\end{aligned}
$$

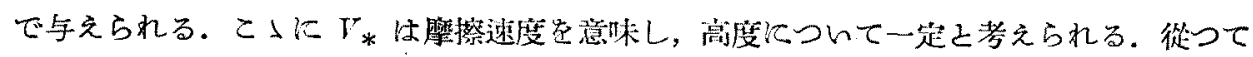

$$
\left\langle w^{2}\right\rangle_{1}\left|<w^{2}\right\rangle_{2}=\tau_{0,2} / \tau_{0, z_{1}}=Z_{\ddot{2}} / Z_{1}
$$

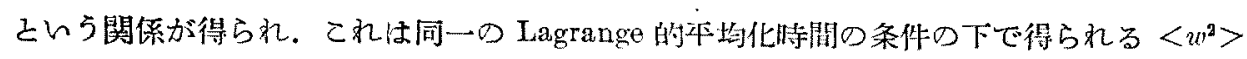

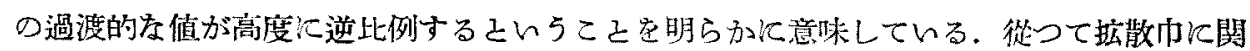

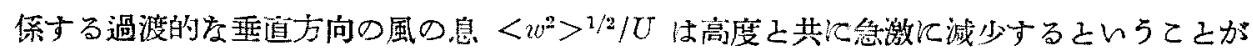
容易江示され，結局

$$
\frac{\left\langle z^{2}\right\rangle_{1}{ }^{1 / 2}}{\left\langle z^{2}\right\rangle_{2}{ }^{1 / 2}}=\frac{U_{2}}{U_{1}} \cdot \frac{\left\langle w^{2}\right\rangle_{1}}{\left\langle w^{2}\right\rangle_{2}}=\frac{\log \frac{Z_{2}}{Z_{0}}}{\log \frac{Z_{1}}{Z_{0}}} \cdot \frac{Z_{2}}{Z_{1}}
$$

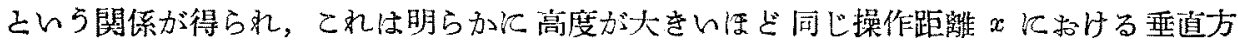
向の煙の搪散の過渡的在巾は小さんといらことを示している。

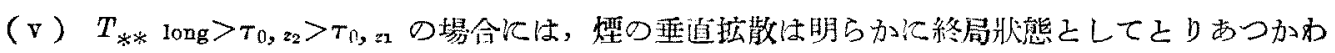

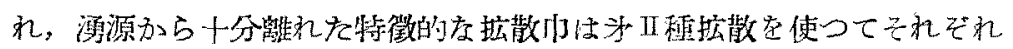

$$
\begin{aligned}
& \left\langle z^{2}>_{1}^{1 / 2} \sim\left\langle w^{2}>_{1}^{1 / 2} \cdot \tau_{1,} \varepsilon_{1},\right.\right. \\
& \left\langle z^{2}\right\rangle_{2}^{1 / 2} \sim\left\langle w^{2}\right\rangle_{2}^{1 / 2} \cdot \tau_{1,}, 22
\end{aligned}
$$

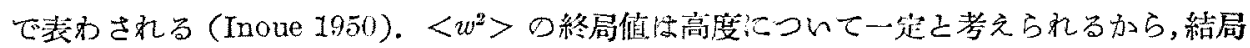

$$
\frac{\left\langle z^{2}\right\rangle_{1}^{1 / 2}}{\left\langle z^{2}\right\rangle:^{1 / 2}} \approx \frac{\tau_{0, z_{1}}}{\tau_{0, z_{2}}}
$$

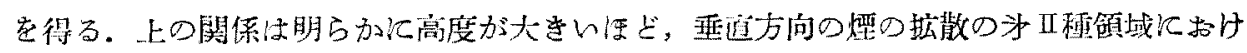
る終局的素巾が大をくなるこをを示している。

これらの絬果は Suttonの未解の問題汇対する可成り满足な解答之見なされるであるら。

\section{§. 結 び}

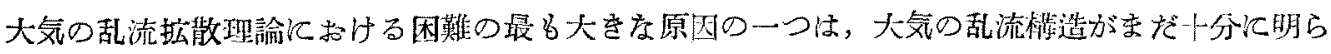

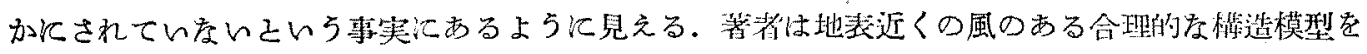

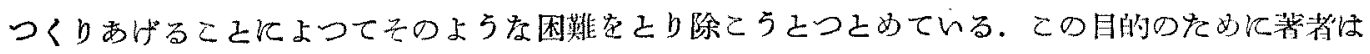

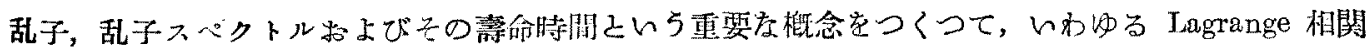
係数 $R(\xi)$ の函数を得ることに成功した. ての $R(\xi)$ は Lagrange 的操作㭙問 $\xi$ の函数であるば

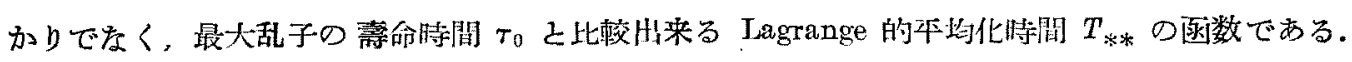


上の三つの時間量を相互に比較して，乱流㹡散の過渡斨態之終局狀態の概念ばかりでなく，乱流拡 散ゆの为I種及び为II種領域の概念が得られる。

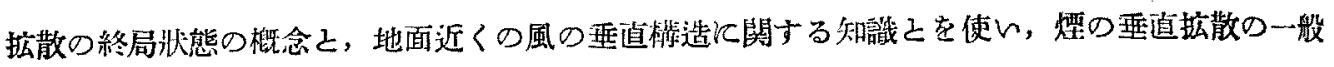
的性質が次のよ5に得られる：

（1）対数風速分布の条件では，操作距離之地表面の粗度さが共に一起保をれるならば，煙の

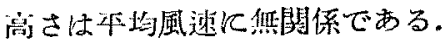

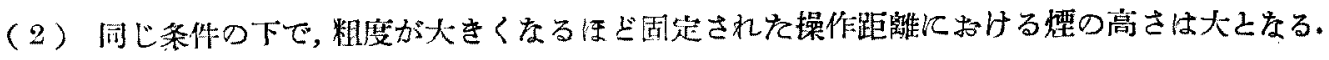

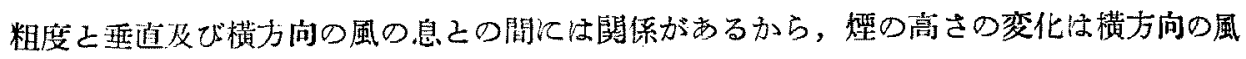
の息之関係づけられるここが䗇来るとの量は風向の変動の大をさによつて指示される. これらの結果は F. A. Record の実驗結果之一般的K一致するもの之考えられる。

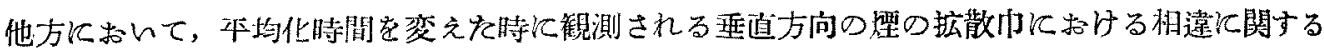

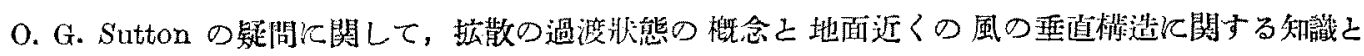
を使つて二，三の会理的索欲明が得られている。

\section{文献}

Deacon, E. L., 1949: Vertical Diffusion in the Lowest Layers of the Atmosphere. Q. J. Roy. Meteor. Soc., 75, 89.

Inoue, E., 1950 : On the Turbulent Diffusion in the Atmosphere, I. 気象集誌, 28, 441.

_ 1951 a: On the Turbulent Diffusion in the Atmosphere, II. 妾象集誌, $29,246$.

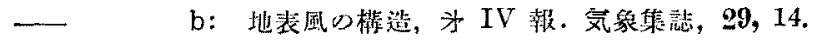

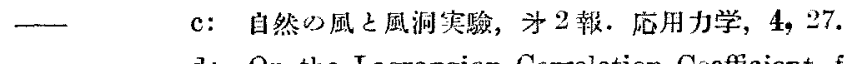

d: On the Lagrangian Correlation Coefficient for the Turbulent Diffusion and Its Application to the Atmospheric Phenomena. (To be published.)

195: : Interrelation between the Structure of Wind and Its Observation. (To be published.)

Kolmogoroff, A. N., 1941: The Local Structure of Turbulence in Incompressible Viscous Fluid for very Large Reynolds' Number. C. R. (Doklady) Acad. Sci. URSS, 31, 301.

Record, F. A., 1951: An Investigation of the Diurnal Variation in the Behavior of Smoke from a Continuous Point Source at Ground Level. (To be published.)

Sutton, O. G., 1932: A Theory of Eddy Diffusion in the Atmosphere. Proc. Roy. Soc. A, 135, 143. 1934: Wind Structure and Evaporation in a Turbulent Atmosphere. Proc. Roy. Soc. A, 146, 701.

1947: The Theoretical Distribution of Air-Borne Pollution from Factory Chimneys. Q. J. Roy. Meteor. Soc., 73, 426.

1949: The Application to Micrometeorology of the Theory of Turbulent Flow over Rougin Surface. Q. J. Roy. Meteor. Soc., 75, 335.

1951: Some Unsolved Problems in the Physics of the Earth's Boundary Layer. (To be published.)

Taylor, G. I., 1921: Diffusion by Continuous Movements. Proc. London Math. Soc., 90, 196. 